\title{
Piroxicam induced submassive necrosis of the liver
}

\author{
D Paterson, P Kerlin, N Walker, S Lynch, R Strong
}

\begin{abstract}
Several widely used non-steroidal antiinflammatory drugs have been reported as causing severe hepatitis. Three cases of severe acute hepatitis have been reported in association with piroxicam. A fatal submassive necrosis that occurred in a 68 year old lady who had received piroxicam for 15 months is described. A 48 year old man who developed submassive hepatic necrosis six weeks after beginning piroxicam but was successfully treated with orthotopic liver transplantation is also reported. Piroxicam may induce submassive necrosis of the liver, probably as an idiosyncratic reaction.

(Gut 1992; 33: 1436-1438)
\end{abstract}

Non-steroidal anti-inflammatory drugs (NSAIDs) are increasingly being recognised as potential hepatotoxins.' Virtually all of those currently available have been reported to cause liver damage ${ }^{2}$ which can range from minor transient abnormalities in liver function tests to fulminant hepatic necrosis. Sulindac, phenylbutazone, diclofenac, and indomethacin are reported to have a higher potential for hepatotoxicity than ibuprofen, naproxen, mefenamic acid, and piroxicam. ${ }^{\prime}$ Severe, sometimes fatal, hepatitis has been most commonly reported in association with the use of diclofenac ${ }^{3-6}$ and sulindac, ${ }^{7-9}$ although fatalities have also been reported with the use of naproxen ${ }^{10}$ and indomethacin."

Piroxicam (Feldene) is an oxicam, unrelated chemically to other available NSAIDs. It is probably the most widely used NSAID worldwide. ${ }^{12}$ Gastrointestinal side effects, most importantly peptic ulceration, are the most common adverse reactions seen. Although changes in liver function tests are very rare, ${ }^{13}$ three cases of severe acute hepatitis secondary to piroxicam have been reported. Two of these patients died ${ }^{14} 15$ and one survived after receiving an emergency liver transplant allograft. ${ }^{16} \mathrm{We}$ describe two cases of fulminant hepatitis related to the use of piroxicam.

Departments of

Gastroenterology and

Hepatology and

Anatomical Pathology

and the Queensland Liver

Transplant Service,

Brisbane, Australia

D Paterson

P Kerlin

N Walker

S Lynch

R Strong

Correspondence to:

Dr P Kerlin, Department of Gastroenterology and Hepatology, Princess

Alexandra Hospital, Ipswich

Road, Woolloongabba

Brisbane, Queensland 4102,

Brisbane,
Australia.

Accepted for publication

15 January 1992
A 68 year old woman was admitted to this hospital in May 1989. In December 1986 she had had a transient ischaemic attack for which she had been given enteric coated aspirin (Ecotrin $300 \mathrm{mg} /$ day). On 31 December 1987 she began piroxicam (Feldene 10-20 mg/day) for pain caused by osteoarthritis of the shoulders, cervical spine, and knees. She remained well generalised pruritus and fatigue. Physical until March 1989, when she presented with examination showed mild icterus but otherwise was entirely normal. At that time, biochemical analysis showed a bilirubin concentration of $39 \mathrm{umol} / \mathrm{l}$, albumin $38 \mathrm{~g} / \mathrm{l}$, alkaline phosphatase (AP) activity $235 \mathrm{U} / 1$, lactate dehydrogenase (LDH) $354 \mathrm{U} / 1$, aspartate transaminase (AST) $680 \mathrm{U} / 1$, alanine transaminase (ALT) $1610 \mathrm{U} / 1$, and gamma glutamyl transferase (GGT) $265 \mathrm{U} / 1$. Her white cell count was $5 \cdot 8 \times 10^{\%} / 1$, with $10 \%$ eosinophils. Both the piroxicam and aspirin were stopped. Ultrasonography showed a normal liver, gall bladder, and biliary tree. Hepatitis A and B, cytomegalovirus, Epstein-Barr virus, Coxiella burnetti, and leptospirosis serology were negative. Stored serum was negative for antibody to hepatitis $\mathrm{C}$, using the second generation Chiron RIBA assay (Chiron Corporation, Emeryville, USA). Serum copper and ceruloplasmin concentrations were within normal limits.

Her hepatic impairment became increasingly severe, and by the end of April 1989 biochemical analysis showed a bilirubin concentration of 426 umol/l, albumin $29 \mathrm{~g} / 1$, AP $187 \mathrm{U} / \mathrm{l}, \mathrm{LDH} 523$ $\mathrm{U} / \mathrm{l}$, AST $1854 \mathrm{U} / \mathrm{l}$, and GGT $36 \mathrm{U} / 1$. Her prothrombin time was 20 seconds. Transjugular liver biopsy on 10 May 1989 showed severe hepatitis with multiacinar necrosis (Fig 1); only occasional lobules remained. The portal areas (Fig 1) and surviving parenchyma (Fig 2) were

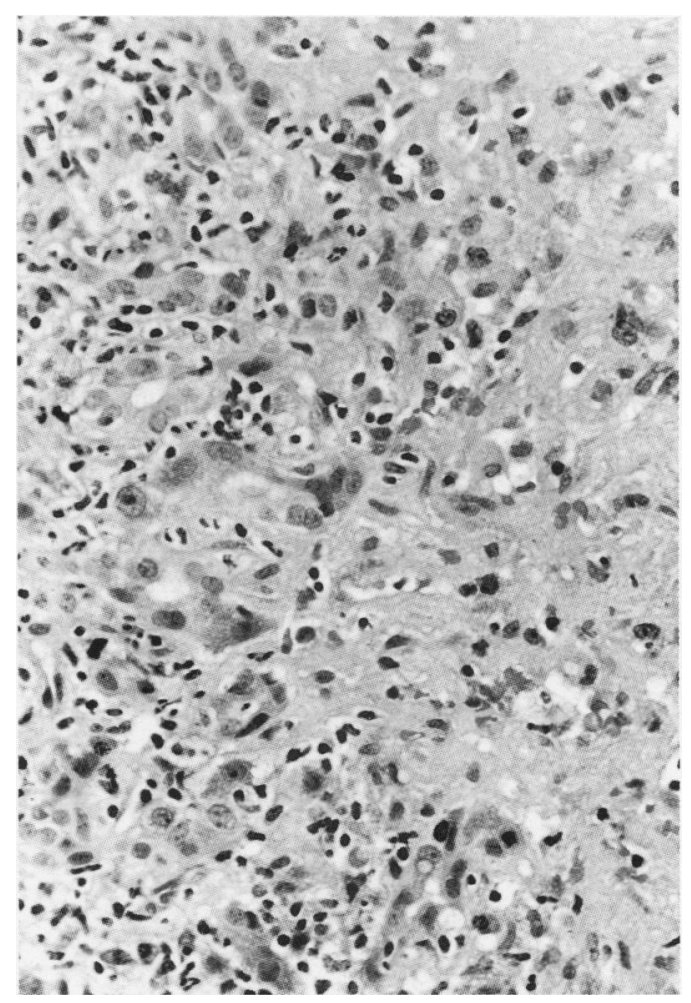

Figure 1: Panacinar necrosis (on right) with pronounced portal ductular hyperplasia and inflammation (on left) (haematoxylin and eosin $\times 340)$. 


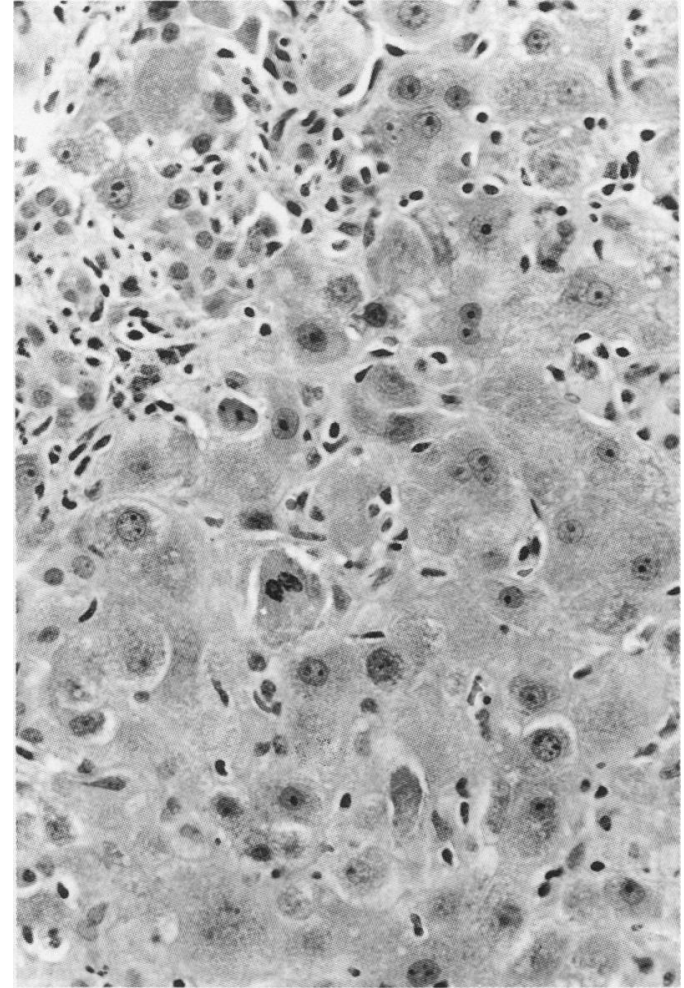

Figure 2: Inflammation of surviving parenchyma (haematoxylin and eosin $\times 350$ ).

heavily infiltrated by lymphocytes, plasma cells, and eosinophils. The appearances were consistent with submassive necrosis caused by drug toxicity. By 12 May the patient had become encephalopathic. Deterioration in her mental status and renal function occurred, and on 31 May she died, three months after the onset of her illness. Necropsy was performed and showed a

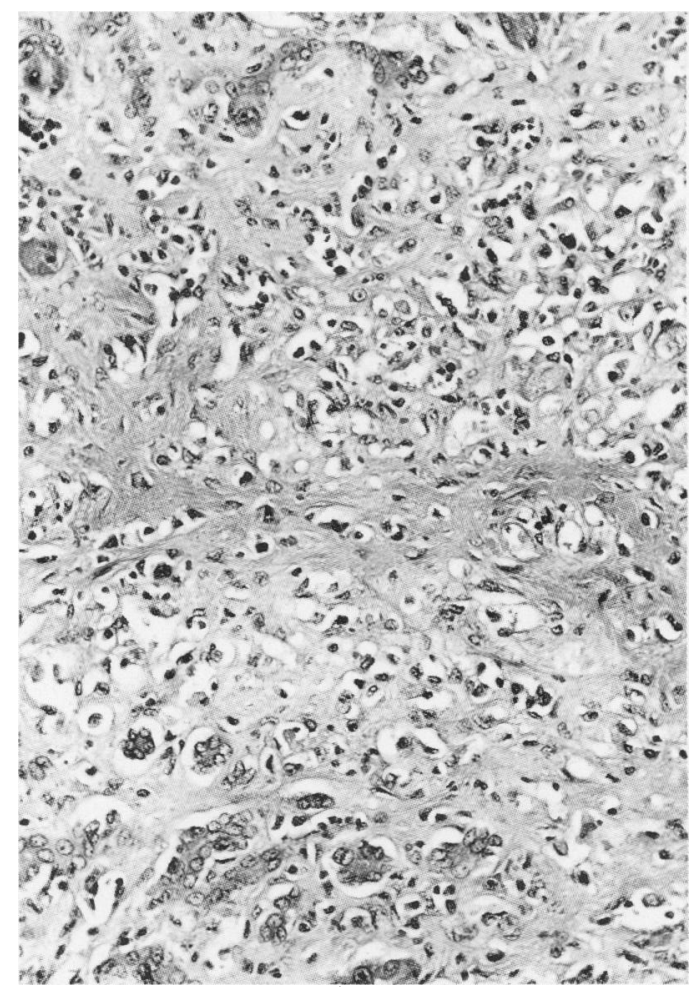

Figure 3: Panacinar necrosis (centre) with peripheral bile ductular hyperplasia (top, bottom) (haematoxylin and eosin $\times 210$ ). small liver $(620 \mathrm{~g})$ with light microscopic changes of submassive necrosis.

CASE 2

A 48 year old man developed stiffness in his joints and lethargy in December 1987, and was begun on piroxicam (Feldene $10 \mathrm{mg}$ ). His arthralgia resolved but six weeks later he developed jaundice, dark urine, and pale stools. Examination at this time showed a firm, enlarged liver. On 16 February 1988 his bilirubin concentration was $243 \mathrm{umol} / \mathrm{l}$, albumin $28 \mathrm{~g} / \mathrm{l}$, international normalised ratio $2 \cdot 4$, AST $1860 \mathrm{U} / 1$, alkaline phosphatase $87 \mathrm{U} / 1, \mathrm{LDH} 471 \mathrm{U} / 1$, and GGT 133 U/l. Ultrasonography and endoscopic retrograde cholangiopancreaticography were normal. Serology for hepatitis A and B, cytomegalovirus, and Epstein-Barr virus and an autoantibody screen were negative. Stored serum from this time has subsequently been shown to be negative for antibody to hepatitis C (RIBA assay, Chiron Corporation). Serum copper and ceruloplasmin concentrations, iron studies, and ferritin were all within normal limits. On 22 February 1988 he developed grade II hepatic encephalopathy and ascites. Acute renal impairment (creatinine $0.37 \mathrm{mmol} / \mathrm{l}$ ) developed on 26 February 1988 and his encephalopathy worsened to grade IV.

Orthotopic liver transplantation was performed on 28 February 1988. Histology showed submassive necrosis (Fig 3). Sixteen days after liver transplantation a deterioration in liver function tests occurred and liver biopsy showed cytomegalovirus inclusion bodies. His platelet count began to fall and bone marrow biopsy showed viral haemophagocytic syndrome. The patient was treated with intravenous ganciclovir. He recovered promptly and has had no further problems 30 months after transplantation.

\section{Discussion}

We believe that the submassive necrosis in these two patients was caused by piroxicam. Metabolic and infectious causes of submassive necrosis are unlikely in view of the negative biochemical and serological tests. Importantly, hepatitis C serology was negative. Sporadic reports of hepatitis associated with widely used drugs have been criticised in the past, because of inability to exclude non-A, non-B hepatitis. ${ }^{17}$

Aspirin was also used by the elderly woman in the first case. Aspirin has been reported to cause hepatotoxicity in recent years. Most patients affected have been young women with connective tissue disorders who receive aspirin regularly in high dosage. ${ }^{2}$ Their liver damage is usually mild, dose dependent, and reversible when the drug is stopped. Several case reports of severe liver damage, some with encephalopathy resembling Reye's syndrome, have been reported with aspirin usage but these have all been in children. ${ }^{2}$ We believe that there is no good evidence that aspirin is responsible for our patient's fulminant liver disease in view of her age and the dosage of aspirin she ingested.

Severe liver damage caused by NSAIDs is usually attributed to 'hypersensitivity' or 
'idiosyncrasy'. This also seems to be the mechanism of piroxicam induced liver damage. There does not seem to be a consistent dose related hepatotoxic effect, even in overdose. Normal liver function tests were recorded after a reported ingestion of $1800 \mathrm{mg}$ piroxicam. ${ }^{18}$ Previous case reports of piroxicam induced submassive necrosis have described the onset of jaundice three days ${ }^{14}$ and three weeks ${ }^{15}$ after beginning piroxicam. Our second patient fits this pattern, with an anset of jaundice approximately six weeks after piroxicam was begun. Most other cases of severe hepatic injury associated with NSAIDs have occurred within weeks to months of starting treatment. ${ }^{3-11}$

The first patient we described presented with jaundice 15 months after beginning piroxicam. There is precedence for this long duration between introduction of the drug and the development of hepatitis. The NSAIDs pirprofen, benoxaprofen, and diclofenac caused fatal hepatitis 9,10 , and 11 months respectively after starting therapy. ${ }^{19-21}$ In a large study of isonazid associated hepatitis, $54 \%$ of patients presented after having received the drug for more than two months and several received the drug for more than 12 months before presentation. ${ }^{22}$

Two of the three previously reported cases of severe hepatitis caused by piroxicam occurred in women in their $60 \mathrm{~s}^{14}{ }^{15}$ Treatment with corticosteroids was begun in each of these without success, with death occurring 105 and 53 days respectively after the onset of jaundice. Our first patient, also in her $60 \mathrm{~s}$, survived three months after the onset of jaundice. She was not treated with corticosteroids. It seems clear that only hepatic transplantation will save such patients with severe hepatic failure. As previously mentioned, there is a report of successful liver transplantation in a 36 year old man with acute hepatic failure related to piroxicam usage. ${ }^{16}$ The long term prospects of the 48 year old man who underwent liver transplant are good. We recommend liver transplantation as the only treatment likely to be successful in drug related submassive necrosis of the liver.

1 Tolman KG. Hepatotoxicity of Antirheumatic Drugs. f Rheumatol 1990; 17 (suppl 22): 6-11.

2 Prescott LF. Effects of non-narcotic analgesics on the liver. Drugs 1986; 32 (suppl 4): 129-47.

3 Breen EG, McNicholl J, Cosgrove E, McCabe J, Stevens FM. Fatal hepatitis associated with diclofenac. Gut 1986; 27 : 1390-3.

4 Dunk AA, Walt RP, Jenkins WJ, Sherlock SS. Diclofenac hepatitis. $B M \mathcal{F} 1982$; 284: 1605-6.

5 Diggory P. Golding RL, Lancaster R. Renal and hepatic impairment in association with diclofenac administration. Postrgrad Med F 1989; 65: 507-8.

6 Iveson TJ, Ryley NG, Kelly PMA, et al. Diclofenac associated hepatitis. Hepatology 1990; 10: 85-9.

7 Daniele B, Pignata S, D'Agostino L, et al. Sulindac-induced severe hepatitis. Am $\mathcal{F}$ Gastroenterol 1988; 83: 1429-31.

8 Park GD, Spector R, Headstream T, Goldberg M. Serious adverse reactions associated with sulindac. Arch Intern Med 1982; 142: 1292-4.

9 Klein SM, Khan MA. Hepatitis, toxic epidermal necrolysis and pancreatitis in association with sulindac therapy. f R heumatol 1983; 10: 512-3.

10 Giarelli L, Falconieri G, Delendi M. Fulminant hepatitis following naproxen administration. Hum Pathol 1986; 17: 1079.

11 Kelsey WM, Scharyj M. Fatal hepatitis probably due to indomethacin. FAMA 1967; 199: 586-7.

12 Nuki G. Non-steroidal analgesic and anti-inflammatory agents. $B M \mathcal{F}$ 1983; 287: 39-43.

13 Brogden RN, Heel RC, Speight TM, Avery GS. Piroxicam: a review of its pharmacological properties and therapeutic efficacy. Drugs 1981; 22: 165-87.

14 Lee SM, O'Brien CJ, Williams $\mathbf{R}$, et al. Subacute hepatic necrosis induced by piroxicam. $B M \mathcal{F} 1986 ; 293$ : $540-1$.

15 Planas R, De Leon R, Quer JC, et al. Fatal submassive necrosis of the liver associated with piroxicam. Am $\mathcal{F}$ Gastroenterol 1990; 85: 468-70.

16 Bismuth H, Samuel D, Gugenheim J, et al. Emergency liver transplantation for fulminant hepatitis. Ann Intern Med transplantation for

17 O'Brien WM. Adverse reactions to nonsteroidal antiinflammatory drugs. $A m \mathcal{F}$ Med 1986; 80 (suppl 4B): 70-80.

18 Vale JA, Meredith TJ. Acute poisoning due to non-steroidal anti inflammatory drugs. Med Toxicol 1986; 1: 12-31.

19 Danan G, Trunet P, Bernuau J, et al. Pirprofen-induced fulminant hepatitis. Gastroenterology 1985; 89: 210-3.

20 Duthie A, Glanfield P, Nicholls A, et al. Fatal cholestatic jaundice in elderly patients taking benoxaprofen [Letter]. $B M \mathcal{F}$ 1982; 285: 62 .

21 Ouellette GS, Slitzkey BE, Gates JA, Lagarde S, West AB. Reversible hepatitis associated with diclofenac. $\mathcal{f}$ Clin Gastroenterol 1991; 13: 205-10.

22 Black M, Mitchell JR, Zimmerman HJ, Ishak KG, Epler GR. Isoniazid-associated hepatitis in 114 patients. Gastroenterology 1975; 69: 289-302. 